DOI 10.37882/2500-3682.2021.08.01

\title{
СВЯЗЬ УЧЕБНОЙ МОТИВАЦИИ И МОТИВАЦИИ К БУДУЩЕЙ ПРОФЕССИОНАЛЬНОЙ ДЕЯТЕЛЬНОСТИ У СТУДЕНТОВ-ПЕРВОКУРСНИКОВ
}

\section{THE RELATIONSHIP BETWEEN EDUCATIONAL MOTIVATION AND MOTIVATION FOR FUTURE PROFESSIONAL ACTIVITY AMONG FRESHMEN STUDENTS}

\section{O. Benkova \\ T. Artyukhova \\ T. Shelkunova}

Summary: The article deals with the theoretical aspects of educational and professional motivation at the student age. The results of an experimental study of educational motivation and motivation for professional activity among first-year students are presented; Using Spearman's rank correlation method, the connections of the components of educational motivation with the types of motivation for professional activity and leading professional motives in freshmen were revealed.

Keywords: educational motivation, motivation for professional activity, professional motives, first-year students.
Бенькова Оксана Анатольевна

к.nсх.н., дочент, Сибирский федеральный университет (2. Красноярск)

ShulakovaOA@mail.ru

Артюхова Татьяна Юрьевна

к.nсх.н., дочент, Сибирский федеральный университет

(2. Красноярск)

tartjuchova@mail.ru

Шелкунова Татьяна Васильевна

старший преподаватель, Лесосибирский педагогический институт - филиал Сибирского феедерального университета (2. Лесосибирск) cokolova_t_v@mail.ru

Аннотация: В статье рассмотрены теоретические аспекты учебной и профессиональной мотивации на начальном этапе студенчества. Представлены результаты экспериментального исследования учебной мотивации и мотивации к профессиональной деятельности у студентов первого курса; с помощью метода ранговой корреляции Спирмена выявлены связи компонентов учебной мотивации с типами мотивации профессиональной деятельности и ведущими профессиональными мотивами у студентов-первокурсников.

Ключевые слова: учебная мотивация, мотивация к профессиональной деятельности, профессиональные мотивы, студенты-первокурсники.

\section{Теоретические основы исследования}

Большинство исследователей рассматривают категорию «учебно-профессиональная мотивация», связывая воедино учебную мотивацию и мотивацию к будущей профессиональной деятельности. В контексте нашего исследования целесообразно рассмотреть эти понятия в отдельности.

Учебная мотивация или мотивация учебной деятельности - один из факторов, способствующих успешному достижению целей обучения, детерминирующих учебную деятельность студента и стимулирующих его активность в период обучения в вузе.

Как указывает И.А. Зимняя, «...учебная мотивация определяется как частный вид мотивации, включенной в деятельность учения, учебную деятельность...» [3, с. 224]; В.И. Мельников мотивацию обучения рассматривает как «средство побуждения учащегося к продуктивной познавательной деятельности, активному освоению содержания образования...» [9, с. 62].

Структуру учебной мотивации составляют различ- 
ные виды мотивов. По мнению А.К. Марковой, «...мотив учения - это направленность ... на различные стороны учебной деятельности...» [8, с. 11], разделяя все мотивы учения на познавательные и социальные, где первые связаны с содержанием и процессом выполнения учебной деятельности, а вторые - с взаимодействием обучающегося с окружающими людьми. Подобную позицию мы встречаем у В.И. Мельникова, но помимо познавательных и социальных мотивов, ученый добавляет еще ряд мотивов: прагматические, профессионально-ценностные, эстетические, статусно-позиционные, коммуникативные, традиционно-исторические, утилитарнопрактические, учебно-познавательные, неосознанные [9]. Именно последние для нас представляют интерес, т.к. проявляются в отсутствии интереса к процессу обучения, непонимании смысла получения образования.

В структуру академической мотивации Т.О. Гордеева, О.А. Сычев, Е.Н. Осин включают такие мотивации, как познавательная, достижения, саморазвития, самоуважения, интроецированную и экстернальную [2].

Изучая мотивацию учения студентов педагогического вуза, С.А. Пакулина, С.М. Кетько выделили внутреннюю и внешнюю мотивацию учения. В структуру внутренней мотивации входят внутренние мотивы поступления в вуз, широкие учебно-познавательные мотивы, мотивы самообразования и релевантные профессиональные мотивы. Внешняя мотивация учения включает внешние мотивы поступления в вуз, познавательные мотивы, иррелевантные профессиональные мотивы [10].

Итак, можем отметить, что учебная деятельность студентов стимулируется и регулируется целым комплексом мотивов, от которых во многом зависит становление и развитие мотивации к будущей профессиональной деятельности.

Автор Е.А. Колесник рассматривает мотивацию студентов к профессиональной деятельности «...как систему ценностей и целей, которая побуждает студентов к активному усвоению знаний, овладению умениями и навыками ...» [6, с. 754].

Отметим, что относительно структуры мотивации к профессиональной деятельности среди исследователей нет единой позиции.

Так, Э.С. Чугунова выделяет доминантный, ситуативный, конформистский типы профессиональной мотивации [11]; автор К.С. Козляков вычленяет личностный, учебно-познавательный, проективно-практический и профессиональный компоненты [5]; исследователями И.А. Игнатковой, А.В. Крыловой определены такие типы мотивации как: установка на профессию, внутренняя, внешняя положительная и внешняя отрицательная мотивация [4]; Л.А. Верещагина фиксирует следующие ведущие мотивы профессиональной деятельности: мотивы собственного труда, социальной значимости профессии, самоутверждения в профессии и мотивы профессионального мастерства [1].

По мнению А.В. Лапшовой, П.А. Грашиной, Е.А. Ураковой, «...мотивация студентов к профессиональной деятельности, формируемая в процессе освоения учебной деятельности, может быть представлена совокупностью познавательных, профессиональных и личностных мотивов, побуждающих к освоению специальности, вызывающих активность и определяющих профессиональную направленность. Система мотивов отражает единство побуждений студента к учению и профессиональной деятельности и позволяет ему активно стремиться к овладению общекультурными, учебно-познавательными и профессиональными компетенциями...» [7, с. 164].

Итак, анализ категориального аппарата исследования позволил сформулировать гипотезу о связи компонентов учебной мотивации студентов-первокурсников с типами мотивации профессиональной деятельности и ведущими профессиональными мотивами.

\section{База и методы исследования}

Экспериментальное исследование связи учебной мотивации и мотивации к профессиональной деятельности у студентов-первокурсников осуществлялось на базе ФГАОУ ВО «Сибирский федеральный университет». В констатирующем эксперименте приняли участие студенты 1 курса различных институтов. Выборка исследования составила 100 респондентов.

В экспериментальной работе применялся следующий диагностический инструментарий: методика «Мотивация учения студентов педагогического вуза» С.А. Пакулиной, С.М. Кетько, (содержание методики позволяет применять ее также для диагностики мотивации учения студентов, обучающихся на непедагогических направлениях подготовки); опросник «Шкалы академической мотивации» Т.О. Гордеевой, О.А. Сычева, Е.Н. Осина; методика диагностики мотивации и установки на профессиональную деятельность И.А. Игнатковой, А.В. Крыловой; «Опросник для изучения ведущих мотивов профессиональной деятельности» Л.А. Верещагиной.

При обработке экспериментальных данных с целью выявления связи учебной мотивации и мотивации к профессиональной деятельности у студентов-первокурсников применялся метод ранговой корреляции Спирмена с использованием программы для статистической обработки данных IBM SPSS Statistics Standard Edition. 


\section{Результаты исслеАования}

На первом этапе осуществлялась диагностика учебной мотивации и мотивации к профессиональной деятельности у студентов-первокурсников. На основании диагностических данных, полученных по методике «Мотивация учения студентов педагогического вуза», мы можем сделать вывод, что для 92 \% первокурсников характерна внешняя мотивация учения, включающая в себя внешние мотивы поступления в университет, узкие познавательные мотивы и иррелевантные профессиональные мотивы. Подавляющее большинство обследованных первокурсников имеет тенденцию к продолжению учебной деятельности, исходя из присутствия внешнего подкрепления и отдавая предпочтение выполнению элементарных и не требующих больших временных затрат заданий; их мотивы обучения в вузе не связаны с самим процессом учения; они еще не адаптировались к вузовской системе обучения. Только у 8 \% респондентов диагностирована внутренняя мотивация учения, включающая в себя внутренние мотивы поступления в вуз, широкие учебно-познавательные мотивы и мотивы самообразования, релевантные профессиональные мотивы. Этим студентам интересна профессия, они стремятся успешно учиться, приобретать глубокие знания; получают интеллектуальное удовлетворение от процесса обучения, активны и самостоятельны, предпочитают задания оптимальной трудности; для них свойственна продуктивная адаптация к вузовской среде.

Исходя из результатов диагностики, полученных при обследовании студентов по опроснику «Шкалы академической мотивации», можем сделать вывод, что у 32 \% студентов-первокурсников ведущей является познавательная мотивация, для них характерно стремление понять изучаемый предмет, им интересен сам процесс познания. У 24 \% респондентов преобладает мотивация самоуважения; за счет достижений в учебе они ощущают собственную значимость, важность. 20 \% студентов амотивированы, они не видят смысла в учебе, не испытывают к ней интереса. У 12 \% первокурсников преобладает экстернальная мотивация; они учатся по необходимости, чтобы избежать проблем. У 12 \% студентов ведущая мотивация - интроецированная; при которой студены учатся из чувства долга перед значимыми людьми. Только для $8 \%$ респондентов свойственна мотивация достижения; при которой характерно стремление достичь высоких результатов в учебе. И всего лишь у 8 \% первокурсников ведущей является мотивация саморазвития; обучаясь в вузе, они стремятся развивать свои способности и потенциал.

Исходя из данных, полученных по методике диагностики мотивации и установки на профессиональную деятельность, отметим, что у 40 \% студентов преобладает внутренняя мотивация, связанная с процессом и результатом профессиональной деятельности. У $20 \%$ первокурсников выявлена внешняя положительная мотивация, связанная с материальным стимулированием, престижем. Для 40 \% испытуемых свойственна внешняя отрицательная мотивация, т.е. преобладают мотивы, не связанные с процессом и результатами профессиональной деятельности и имеющие негативную эмоциональную окраску избегания.

Сравнивая среднеарифметические показатели, полученные в обследуемой группе по шкалам опросника Л.А. Верещагиной, делаем вывод, что для респондентов наиболее значимы мотивы собственного труда, отражающие ориентацию на общую трудовую занятость, без учета специфики профессии. На втором месте - мотивы самоутверждения в профессии; т.е. студенты первого курса ориентированы на высокий уровень достижений в профессиональной деятельности. Мотивы социальной значимости профессии занимают третье место. Это позволяет нам утверждать, что первокурсники не слишком высоко оценивают общую пользу и значимость труда. Последнее место занимают мотивы профессионального мастерства; т.е. пока для испытуемых мало свойственно стремление быть признанным в профессиональной деятельности.

На следующем этапе экспериментального исследования на основании диагностических данных нами был проведен корреляционный анализ с использованием метода ранговой корреляции Спирмена. Принимались во внимание коэффициенты корреляции для уровней значимости $\mathrm{p}<0,05$ и $\mathrm{p}<0,01$.

В результате корреляционного анализа были установлены следующие корреляционные связи. Составляющая академической мотивации «Мотивация познания» положительно коррелирует со следующими мотивами профессиональной деятельности - «Установка на профессию» $(r=0,836 ; p<0,01)$; «Внешняя положительная мотивация» $(r=0,459 ; p<0,05)$; «Мотивы собственного труда» $(r=0,701 ; p<0,01)$; «Мотивы социальной значимости профессии» $(r=0,694 ; p<0,01)$; «Мотивы самоутверждения в профессии ( $r=0,643 ; p<0,01)$; «Мотивы профессионального мастерства» $(r=0,965 ; p<0,01)$. Итак, чем выше познавательная мотивация студентов-первокурсников, тем в большей степени у них сформированы представления о профессиональной деятельности; внешние опосредованные мотивы, связанные с процессом труда; ориентация на деятельность без учета специфики профессии. При этом чем больше у первокурсников выражена мотивацией познания, тем выше они оценивают пользу и значимость труда, тем больше хотят добиться высоких результатов в профессиональной деятельности.

Выявлена связь показателей «Мотивация достижения» и «Мотивация саморазвития» в учебной деятель- 
ности с такими профессиональными мотивами как «Установка на профессию» $(r=0,827 ; r=0,770 ; p<0,01)$; «Внутренняя мотивация» $(r=0,396 ; \mathrm{p}<0,01 ; \quad r=0,659$; $\mathrm{p}<0,05)$; «Внешняя положительная мотивация» $(\mathrm{r}=0,515$; $p<0,01 ; r=0,499 ; p<0,05)$; «Мотивы собственного труда» $(r=0,749 ; r=0,785 ; p<0,01)$; «Мотивы социальной значимости профессии» $(r=0,757 ; r=0,612 ; p<0,01)$; «Мотивы самоутверждения в профессии $(r=0,701 ; r=0,656 ; p<0,01)$; «Мотивы профессионального мастерства» $(r=0,808 ; r=0,748$; $\mathrm{p}<0,01)$. Следовательно, чем больше стремление первокурсников добиваться высоких результатов и развивать свои способности и потенциал в учебной деятельности, тем в большей мере студенты ориентированы на социальные требования к профессии; тем больше у них проявляется внутренняя мотивация, связанная непосредственно с процессом труда, и внешняя положительная мотивация, опосредованно связанная с профессиональной деятельностью; тем больше они ориентированы на общую занятость в профессии; нацелены на постоянное освоение новых умений и знаний; мотивированы на самовыражение и стремление быть признанными в профессии.

Установлены корреляционные связи параметра «Мотивация самоуважения» в учебной деятельности со следующими профессиональными мотивами - «Установка на профессию» $(r=0,689 ; p<0,01)$; «Внутренняя мотивация» $(r=0,485 ; p<0,05)$; «Внешняя положительная мотивация» $(r=0,502 ; p<0,05)$; «Мотивы собственного труда» $(r=0,648 ; p<0,01)$; «Мотивы социальной значимости профессии» $(r=0,989 ; p<0,05)$; «Мотивы самоутверждения в профессии ( $r=0,672 ; p<0,01)$; «Мотивы профессионального мастерства» $(r=0,649 ; p<0,01)$. Вероятно, что чем выше желание студента-первокурсника учиться ради повышения собственной самооценки за счет достижений в учебе и ощущения собственной значимости, тем в большей степени сформированы установки на профессию; внутренняя и внешняя положительная мотивация; нацеленность на постоянное совершенствование профессиональных умений; стремление быть лучшим. При этом выявлена отрицательная корреляционная связь между мотивацией самоуважения в учебной деятельности и внешней отрицательной мотивацией ( $\mathrm{r}=-0,419$; $\mathrm{p}<0,05)$. Следовательно, чем больше у студента проявляется желание учиться ради ощущения собственной значимости, тем в меньшей степени формируются мотивы, не связанные непосредственно с процессом и результатом профессиональной деятельности, но имеющие негативную эмоциональную окраску (осуждение, критика, наказание и т.п.).

Выявлены отрицательные корреляционные взаимосвязи параметров «Интроецированная мотивация» и «Экстернальная мотивация» с такими мотивами профессиональной деятельности как «Установка на профессию» $(r=-0,671 ; r=-0,825 ; p<0,01)$; «Внутренняя мотивация» $(r=-$
0,416; $r=-0,442 ; p<0,05)$; «Внешняя положительная мотивация» $(r=-0,551 ; r=-0,518 ; p<0,01)$; «Мотивы собственного труда» $(r=-0,691 ; r=-0,688 ; p<0,01)$; «Мотивы социальной значимости профессии» $(r=-0,828 ; r=-0,740 ; p<0,01)$; «Мотивы самоутверждения в профессии» $(r=-0,670 ; r=-0,726$; $\mathrm{p}<0,01)$; «Мотивы профессионального мастерства» $(r=-$ $0,751 ; r=-0,856 ; p<0,01)$. Следовательно, чем в большей степени студентов-первокурсников побуждает учиться чувство долга и ощущение стыда перед собой и окружающими, ситуация вынужденности обучения, стремление избежать проблем, необходимость следовать требованиям социума; тем в меньшей степени у них сформированы представления о профессиональной деятельности, внутренняя и внешняя положительная профессиональная мотивация; мотивы собственного труда; тем в большей степени они не видят особой пользы и значимости профессионального труда; не ориентированы на достижение высоких результатов и стремление состояться в профессиональной деятельности.

В результате корреляционного анализа данных установлены отрицательные корреляционные связи параметра «Амотивация» со следующими мотивами профессиональной деятельности - «Установка на профессию» $(\mathrm{r}=-0,607 ; \mathrm{p}<0,01)$; «Внутренняя мотивация» $(\mathrm{r}=-$ $0,436 ; p<0,05)$; «Внешняя положительная мотивация» $(r=-$ 0,554; $p<0,01)$; «Мотивы собственного труда» ( $r=-0,612$; $\mathrm{p}<0,01)$; «Мотивы социальной значимости профессии» $(-r=0,759 ; p<0,01)$; «Мотивы самоутверждения в профессии» $(r=-0,632 ; p<0,01)$; «Мотивы профессионального мастерства» $(r=-0,696 ; p<0,01)$. Вероятно, что, чем больше у первокурсников выражено отсутствие интереса к учебной деятельности, ощущение ее бессмысленности, тем в меньшей мере они ориентированы на социальные требования к профессии и непосредственно на результат труда; тем менее у них проявляется внешняя положительная мотивация, мотивы собственного труда; тем меньше они нацелены на постоянное освоение новых профессиональных знаний и умений; тем менее значимо для них признание в профессиональной деятельности. Выявлена положительная корреляционная связь параметра «Амотивация» с внешней отрицательной мотивацией профессиональной деятельности $(r=0,421 ; p<0,05)$. Это означает, что, чем более первокурсник не заинтересован в учебной деятельности, тем больше у него выражены мотивы избегания, не связанные непосредственно с процессом профессионального труда.

Таким образом, можем сделать вывод, что виды академической мотивации (мотивация познания, достижения, саморазвития, самоуважения; интроецированная и экстернальная мотивация, амотивация) связаны с типами мотивации студентов на профессиональную деятельность и ведущими профессиональными мотивами.

Проанализируем корреляционные связи компонен- 
тов внутренней и внешней мотивации учения.

Установлены положительные корреляционные связи компонента «Внутренние мотивы поступления в вуз» с типами мотивации на профессиональную деятельность «Установка на профессию» $(r=0,765 ; p<0,01)$; «Внутренняя мотивация» $(r=0,561 ; p<0,01)$ и ведущими профессиональными мотивами «Мотивы собственного труда» $(r=0,761 ; p<0,01)$; «Мотивы социальной значимости профессии» $(r=0,514 ; p<0,01)$; «Мотивы самоутверждения в профессии» $(r=0,740 ; p<0,01)$; «Мотивы профессионального мастерства» $(r=0,867 ; p<0,01)$. Следовательно, чем в большей степени у студента-первокурсника проявляются внутренние мотивы поступления в вуз, основанные на его собственной потребности, тем больше студент ориентирован на социальные требования к профессии; тем более у него сформирована внутренняя профессиональная мотивация, основанная на удовлетворенности процессом и результатом деятельности; тем больше у него выражена мотивация собственного труда, высокая оценка пользы и значимости профессиональной деятельности, стремление стать признанным в профессиональном сообществе.

Выявлены положительные корреляционные связи компонента внутренней мотивации учения «Широкие учебно-познавательные мотивы и мотивы самообразования» с типами мотивации на профессиональную деятельность «Установка на профессию» $(\mathrm{r}=0,771 ; \mathrm{p}<0,01)$; «Внутренняя мотивация» $(r=0,448 ; p<0,05)$; «Внешняя положительная мотивация» $(r=0,489 ; p<0,05)$ и ведущими профессиональными мотивами «Мотивы собственного труда» $(r=0,724 ; p<0,01)$; «Мотивы социальной значимости профессии» $(r=0,676 ; p<0,01)$; «Мотивы самоутверждения в профессии» $(r=0,808 ; p<0,01)$; «Мотивы профессионального мастерства» $(r=0,776 ; p<0,01)$. Исходя из выявленных корреляционных связей, можем сделать заключение о том, что, чем выше у студента-первокурсника желание успешно учиться и приобретать глубокие знания, чем больше его потребность самореализовываться в учебной деятельности, проявлять активность и самостоятельность, тем в большей степени он ориентирован на будущую профессиональную деятельность; тем больше развита потребность трудиться с удовольствием, ориентация на процесс труда, нацеленность на постоянное освоение новых знаний и умений.

Установлены значимые корреляционные связи между компонентом внутренней мотивации учения «Релевантные профессиональные мотивы» с типами мотивации на профессиональную деятельность «Установка на профессию» $(r=0,863 ; p<0,01)$; «Внешняя положительная мотивация» $(r=0,440 ; p<0,05)$ и ведущими профессиональными мотивами «Мотивы собственного труда» $(r=0,667 ; p<0,01)$; «Мотивы социальной значимости профессии» $(r=0,692 ; p<0,01)$; «Мотивы самоутверждения в профессии» $(r=0,802 ; p<0,01)$; «Мотивы профессионального мастерства» $(r=0,810 ; p<0,01)$. Следовательно, чем больше первокурсник мотивирован на реализацию себя в профессиональном плане в соответствии с выбранным направлением подготовки, тем более выражена у него ориентация на социальные требования к профессии, внешняя положительная мотивация, направленная на материальное стимулирование, карьерное продвижение, одобрение; ориентация на результат деятельности без учета специфики профессии; нацеленность на освоение новых профессиональных знаний и умений и высокий уровень достижений в профессиональном труде.

Выявлены положительные корреляционные связи компонента «Внешние мотивы поступления в вуз» с типами мотивации на профессиональную деятельность «Установка на профессию» $(r=0,702 ; p<0,01)$; «Внутренняя мотивация» $(r=0,605 ; p<0,01)$; «Внешняя положительная мотивация» $(r=0,563 ; p<0,01) ;$ и ведущими профессиональными мотивами «Мотивы собственного труда» $(r=0,704 ; p<0,01)$; «Мотивы социальной значимости профессии» $(r=0,611 ; p<0,01)$; «Мотивы самоутверждения в профессии» $(r=0,689 ; p<0,01)$; «Мотивы профессионального мастерства» $(r=0,705 ; p<0,01)$. Итак, чем выше внешняя мотивация учения у студентов-первокурсников, проявляющаяся в желании не отставать от сокурсников, добиться уважения преподавателей и одобрения окружающих, избежать осуждения, тем в большей степени первокурсники ориентированы на социальные требования по присвоению будущей профессиональной деятельности; у них формируется внутренняя и внешняя положительная мотивация, хотя, и без учета специфики профессии, но при высокой оценке ее социальной значимости, мотивации на качество выполняемой профессиональной деятельности и стремлении достичь высоких результатов.

Установлены положительные корреляционные связи компонентов внешней мотивации учения «Узкие учебно-познавательные мотивы» и «Иррелевантные профессиональные мотивы» с такими составляющими мотивации профессиональной деятельности - «Установка на профессию» $(r=0,705 ; r=0,686 ; p<0,01)$; «Внутренняя мотивация» $(r=0,591 ; r=0,684 ; p<0,01)$; «Внешняя положительная мотивация» $(r=0,545 ; p<0,01 ; r=0,482 ; p<0,05)$; «Мотивы собственного труда» $(r=0,673 ; r=0,635 ; p<0,01)$; «Мотивы социальной значимости профессии» ( $r=0,517$; $\mathrm{r}=0,583 ; \mathrm{p}<0,01)$; «Мотивы самоутверждения в профессии» $(r=0,736 ; r=0,634 ; p<0,01)$; «Мотивы профессионального мастерства» $(r=0,748 ; r=0,742 ; p<0,01)$. Очевидно, чем более выражена тенденция к осуществлению учебной деятельности, тем в большей мере студенты ориентируются на социальные требования к будущей профессии; внешние стимулы, ради которых они считают нужным прикладывать свои усилия; на результативную деятельность без учета специфики профессионального 
труда, но с нацеленностью на высокий уровень профессиональных достижений.

\section{Выво $\triangle$ b}

Таким образом, в результате корреляционного анализа установлены связи между компонентами учебной мотивации и компонентами мотивации к профессиональной деятельности у первокурсников.

Виды академической мотивации (познания, достижения, саморазвития, самоуважения, интроецированная и экстернальная мотивация, амотивация), компоненты внутренней мотивации учения (внутренние мотивы поступления в вуз, широкие учебно-познавательные мотивы и мотивы самообразования, релевантные профессиональные мотивы) и внешней мотивации учения (внешние мотивы поступления в вуз, узкие познавательные мотивы, иррелевантные профессиональные моти- вы) связаны с типами мотивации на профессиональную деятельность (установка на профессию, внутренняя профессиональная мотивация, внешняя профессиональная положительная мотивация) и ведущими профессиональными мотивами (мотивы собственного труда, мотивы социальной значимости профессии, мотивы самоутверждения в труде, мотивами профессионального мастерства).

Понимание зависимости между учебной и профессиональной мотивацией у студентов уже на начальном этапе обучения в вузе будет способствовать выстраиванию конструктивного взаимодействия с первокурсниками в рамках образовательного процесса с учетом специфики их учебной мотивации и, в свою очередь, позволит создать условия для развития их мотивации к профессиональной деятельности и может выступать значимым прогностическим фактором удовлетворенности получаемой в вузе профессии в будущем.

\section{ЛИТЕРАТУРА}

1. Верещагина, Л.А. Потребности и профессиональные мотивы специалистов в области информационных технологий / Л.А. Верещагина // Психология и педагогика: методика и проблемы практического применения. - 2012. - № 25. - URL: https://cyberleninka.ru/article/

2. Гордеева, Т.0. Опросник «Шкалы академической мотивации» / Т. О. Гордеева, О.А. Сычев, Е.Н, Осин // Психологический журнал. - 2014. - Т. 35 , № 4. C. 96-107.

3. Зимняя, И.А. Педагогическая психология: учебник для вузов / И.А. Зимняя. - М.: Издательская корпорация «Логос», 2000. - 384 с.

4. Игнаткова, И.А. Методика диагностики мотивации и установки на профессиональную деятельность / И.А. Игнаткова, А.В. Крылова // Психология обучения. -2015 . - № 12. - С. 60-66.

5. Козляков, К.С. Формирование учебно-профессиональной мотивации студентов высшего учебного заведения: автореф. дис. ... канд. пед. наук: 13.00 .08 / Козляков Константин Сергеевич. - Калининград, 2013. - 23 с.

6. Колесник, Е.А. К вопросу о профессиональной мотивации как основе успешности обучения студентов вузов / Е.А. Колесник // Здоровье и образование в XXI веке. - 2016. - № 2. - С. 753-756.

7. Лапшова, А.В. К вопросу об особенностях формирования профессиональной мотивации студентов вуза / А.В. Лапшова, П.А. Грашина, Е.А. Уракова // Проблемы современного педагогического образования. - 2019. - № 62-2. - С. 163-165.

8. Маркова, А.К. Формирование мотивации учения в школьном возрасте: пособие для учителя. - М.: Просвещение, 1983. - 96 с.

9. Мельников, В.Е. Мотивация к обучению студентов в вузе как психолого-педагогическая проблема / В.Е. Мельников // Вестник Новгородского государственного университета. - 2016. - № 5. - С. 61-64.

10. Пакулина, С.А. Методика диагностики мотивации учения студентов педагогического вуза / С.А. Пакулина, С.М. Кетько // Психологическая наука и образование. - 2010. - № 1. - С. 1-11.

11. Чугунова, Э.С. Связь профессиональной мотивации и творческой активности инженеров / Э.С. Чугунова // Вопросы психологии. - 1986. - № 4. C. $23-29$. 